\title{
The use of modern physical metallurgy in the development and characterization of special stainless steels
}

\author{
J.-O. NILSSON \\ Department of Physical Metallurgy, Research and Development Centre, AB Sandvik Steel, 81181 \\ Sandviken, Sweden
}

\begin{abstract}
A selection of examples have been made to illustrate the use of microanalytical instruments and thermodynamics in the development of steels. It has been shown that the combined use of electron microscopy, secondary ion mass spectroscopy, atom probe field ion microscopy and the thermodynamic computer program Thermo-Calc is a particularly powerful tool in aquiring a deeper understanding of the the relation between microstructure and properties. It has also been demonstrated that Thermo-Calc can be used routinely in alloy development for predicting phase equilibria.
\end{abstract}

\section{Introduction}

Alloy development has traditionally been largely phenomenological in nature. However, with the widespread use of various kinds of analytical instruments beginning with the electron microscopes during the 1960's, the physical understanding of the relation between microstructure and properties has been developed to such an extent that the design of alloys with specified properties now begins with microstructural design. The most well-known example of this is probably the development of the family of superalloys, and similar but perhaps less spectacular development work on stainless steels for specific niches is performed continually. With the advent of generally accessible thermodynamically based computer programs during the 80 's it has even become possible to calculate phase diagrams from almost first principles. These programs, which include extensive thermodynamic data, in particular for steels, enable the prediction of equilibrium microstructures and therefore provide an extremely powerful tool for alloy development in combination with modern analytical instruments.

The analytical instruments described in the present work are scanning electron microscopy (SEM), analytical transmission electron microscopy (ATEM), atom probe field ion microscopy (APFIM) and secondary ion mass spectroscopy (SIMS). Because of their different advantages, these instruments may be regarded as complementary in many respects; While SEM with its good depth of focus is suited for surface investigations, ATEM is suitable for diffraction analysis and microanalysis with high lateral resolution, APFIM allows imaging with atomic 
resolution in combination with equal elemental sensitivity quantitative chemical analysis and SIMS offers extremely sensitive chemical microanalysis.

To elucidate the interplay of these techniques their use in the development of a selection of stainless steels will be described in some detail. The selection of examples comprises the development of a highly alloyed ferritic-austenitic steel for marine applications, a non-magnetic spring steel for electronic devices and a corrosion resistant high strength maraging steel for medical instruments. To illustrate how these techniques can be used to obtain a deeper physical understanding of structure-property relations an example is taken from a recent microstructural characterization of nickel-base alloys for steam generator tubing. Examples of the use of the commercially available computer program Thermo-Calc for calculating phase equilibria will also be described. Although the selection of examples is rather personal, the techniques they are intended to illustrate can be easily applied to similar problems in other systems and should therefore be of general interest.

\section{Description of experimental techniques}

To facilitate a comparison between the performance of the techniques described in the present article the most important data have been collected in Table 1 below. It should be pointed out that the figures quoted are only approximative and should therefore only be used for a qualitative comparison.

Table 1 Typical values of resolution and detection limit for chemical analysis in SEM, ATEM, SIMS and APFIM.

\begin{tabular}{|l|l|l|l|l|}
\hline Type of technique & $\begin{array}{l}\text { lateral resolution } \\
(\mathbf{n m})\end{array}$ & $\begin{array}{l}\text { depth } \\
\text { resolution }(\mathbf{n m})\end{array}$ & $\begin{array}{l}\text { detection } \\
\text { limit }\end{array}$ & remarks \\
\hline EDX in SEM & 1000 & 1000 & $1 \%$ & $\begin{array}{l}\text { Only elements heavier } \\
\text { than Na can be analysed } \\
\text { quantitatively }\end{array}$ \\
\hline EDX in ATEM & 10 & 100 & $1 \%$ & Same as above \\
\hline SIMS & 1000 & $0.1-1$ & usually $\leq 10 \mathrm{ppm}$ & $\begin{array}{l}\text { Semiquantitative, high } \\
\text { sensitivity to all elements }\end{array}$ \\
\hline APFIM & 1 & 0.2 & $\leq 100 \mathrm{ppm}$ & $\begin{array}{l}\text { Quantitative with equal } \\
\text { detectivity for all } \\
\text { elements }\end{array}$ \\
\hline
\end{tabular}

Examples from scanning electron microscopy in the present investigation have been taken from a JEOL JSEM 840 having an ideal point to point resolution of $4 \mathrm{~nm}$ provided with a LINK AN 10000 unit for energy dispersive X-ray (EDX) analysis and a detector for back scattered electrons (BSE) in addition to the conventional detector for secondary electrons.

Analytical transmission electron microscopy is illustrated by micrographs taken in a JEOL 2000FX provided with an EDX-detector of the same type as that in the SEM. The point to point resolution of the ATEM was $0.28 \mathrm{~nm}$ and the lateral resolution of EDX microanalyses was approximately $10 \mathrm{~nm}$ taking into account beam broadening in a thin foil of typically 100 $\mathrm{nm}$ thickness. ATEM's in general are suitable for crystallographic investigations using electron diffraction analysis. In particular, the use of convergent beam electron diffraction (CBED). in combination with chemical microanalysis makes ATEM a very powerful tool for identifying secondary phases.

Secondary ion mass spectrometry was performed in a Cameca IMS 300 instrument using $\mathrm{Cs}^{+}$ and $\mathrm{O}_{2}{ }^{+}$as primary ions. The negatively charged secondary ions emitted from the surface were 
used to obtain mass-resolved ion images. This technique has a lateral resolution of about 1000 $\mathrm{nm}$ and has the advantage of being sensitive to all elements and isotopes. For instance, the detection limit of boron is less than $10 \mathrm{ppm}$. This makes SIMS suitable for investigating phenomena such as boron segregation in steels, examples of which will be given below. However, it should be pointed out that SIMS is not a quantitative technique and is therefore only suitable for qualitative purposes.

Atom probe field ion microscopy will be illustrated by examples taken from one of the microscopes built at Chalmers University of Technology (1). APFIM (2) is a technique that combines very high lateral resolution, $1 \mathrm{~nm}$, and depth resolution, $0.2 \mathrm{~nm}$, with a detection limit that is below 0.01 at $\%$ for all elements without exception. Atom probe analysis is performed by ripping atoms off the surface of a needle-shaped specimen having a radius smaller than $100 \mathrm{~nm}$ by a high electric field. A field strength of typically $35 \mathrm{GV} / \mathrm{m}$ is required to remove and ionize the surface atoms of the needle. The ions from a selected area on the specimen surface pass through a time-of-flight spectrometer and hit a detector. The mass-tocharge ratio of the ions reaching the detector is calculated by measuring their flight time. A disadvantage is that specimen preparation is rather time-consuming. Moreover, as can be realized from the small radius of curvature of the specimen the volume investigated is rather limited. However, this can be compensated for by removing surface layers of atoms gradually by field evaporation and/or further electropolishing.

The thermodynamic computer program Thermo-Calc developed in the Department of Physical Metallurgy at the Royal Institute of Technology in Stockholm (3) was used to calculate phase equilibria. Owing to extensive thermodynamic data for steels it is very well suited for predicting phase diagrams for steels and is therefore an invaluable tool in development work. It is capable of computing individual phase equilibria and complete equilibrium diagrams for a given system by minimizing the Gibbs' free energy. Since it is not capable of describing the kinetics of phase transformations and it must be realized that commercial steels are used invariably in metastable states it can be understood that the results from Thermo-Calc have to be treated with some caution and also supplemented by careful microstructural characterization using analytical instruments such as those described above.

\section{Alloys}

The alloys selected for demonstrating the above-mentioned techniques are as follows; The ferritic-austenitic SAF $2507^{\mathrm{TM}}$, the manganese-bearing non-magnetic austenitic steel 13RM19 ${ }^{\mathrm{TM}}$, the stainless maraging steel $1 \mathrm{RK} 91^{\mathrm{Tm}}$ and the nickel-base alloys Alloys 600 and 690 . Their chemical compositions are given in Table 2 below.

Table 2 Nominal chemical composition of alloys under consideration (wt\%)

\begin{tabular}{|c|c|c|c|c|c|c|c|c|c|c|}
\hline Alloy & $\mathrm{C}$ & $\mathrm{Si}$ & $\mathrm{Mn}$ & $\mathrm{Cr}$ & $\mathrm{Ni}$ & Mo & $\mathrm{Cu}$ & $\mathrm{N}$ & $\mathrm{Ti}$ & $\mathrm{Fe}$ \\
\hline SAF $2507^{\mathrm{TM}}$ & $\leq 0.03$ & 0.8 & 1.2 & 25.0 & 6.9 & 4.0 & $\leq 0.5$ & 0.27 & - & bal. \\
\hline $13 \mathrm{RM} 19^{\mathrm{TM}}$ & 0.10 & 0.8 & 6.0 & 18.5 & 7.0 & - & - & 0.25 & - & bal. \\
\hline $1 \mathrm{RK} 91^{\mathrm{TM}}$ & $\leq 0.02$ & 0.2 & 0.3 & 12.0 & 9.0 & 4.0 & 2.0 & - & 1.0 & bal. \\
\hline Alloy 600 & 0.02 & 0.35 & 0.8 & 16.3 & 72.5 & $\leq 0.5$ & $\leq 0.5$ & - & 0.3 & 9.3 \\
\hline Alloy 690 & 0.02 & 0.3 & 0.3 & 30.0 & 60.0 & 0.5 & 0.1 & - & 0.4 & 9.0 . \\
\hline
\end{tabular}

TMTrade mark of Sandvik Steel 


\section{Demonstrating examples}

\subsection{Highly alloyed duplex stainless steel}

Duplex (ferritic-austenitic) steels are used in various applications in marine environments where a combination of mechanical strength and corrosion resistance in sea water is required (4). Pitting resistance, which is an essential property in these environments, can be increased by alloying with chromium, molybdenum and nitrogen. This has been taken advantage of in the recent development of the duplex stainless steel SAF 2507 (5), the pitting resistance of which in chloride containing environments is surpassed only by certain and much more expensive nickel base alloys and highly alloyed austenitic steels. Although chromium, molybdenum and nitrogen are beneficial to corrosion resistance it must be borne in mind that nitrogen may cause precipitation of various nitrides while chromium and molybdenum enhance the formation of intermetallic secondary phases such as $\sigma$-phase, $\chi$-phase and R-phase. The producer of such steels is therefore faced with the delicate balance between desired corrosion resistance, on one hand, and adequate structural stability to guarantee a precipitate-free end product, on the other hand. It is therefore essential to assess the relevant time-temperature-precipitation (TTP) diagram, which enables an estimation of required cooling rates and heat treatment times.

Before determining the TTP-diagram it is often convenient to calculate isothermal sections at various temperatures as an indication of the types of phases that can be expected during isothermal aging. An example of this is given in Fig 1 representing an isothermal section of the Fe-Cr-Mo-Ni system at $800^{\circ} \mathrm{C}$ calculated assuming fixed fractions of $4 \%$ molybdenum and $0.3 \%$ nitrogen. The composition of SAF 2507 corresponds to the filled square, i.e. the phase field containing $\sigma$-phase, $\mathrm{Cr}_{2} \mathrm{~N}(\varepsilon)$ and austenite $(\gamma)$ in equilibrium. However, bearing in mind the uncertainty of thermodynamic data for $\chi$-phase in combination with the fact that equilibrium is seldom obtained, the presence of a phase field containing $\chi$-phase for compositions close to that of SAF 2507 suggests that it is possible to form $\chi$-phase in practice.
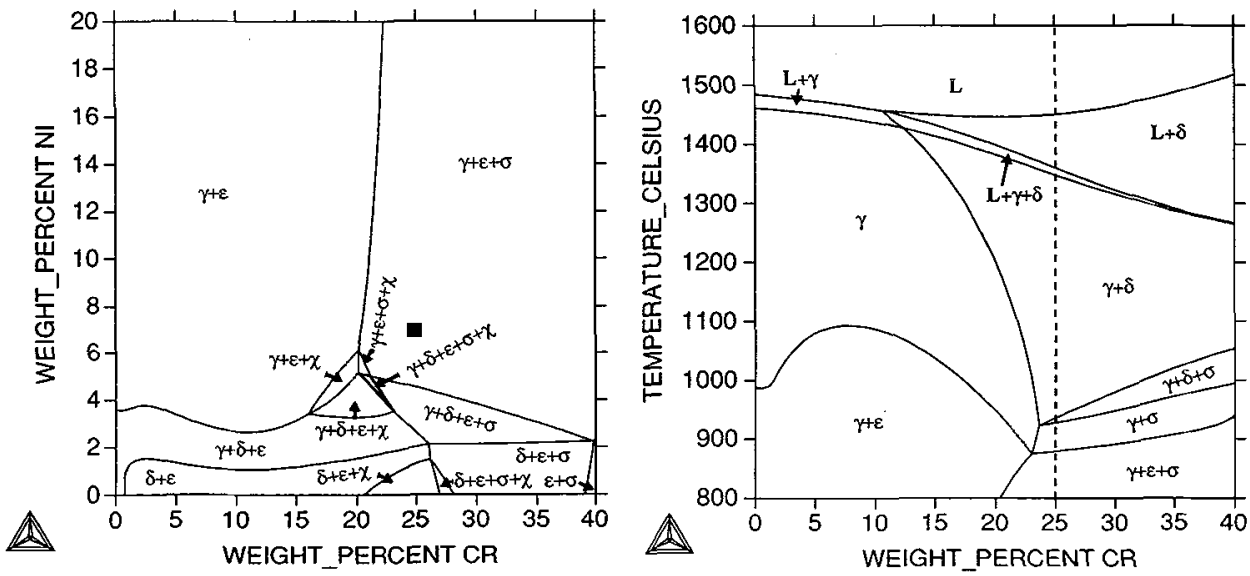

Fig 1 Isothermal section of the Fe-Cr-Ni-Mo-N Fig 2 Computer calculated isopleth diagram above system at $800^{\circ} \mathrm{C}$ calculated using Thermocalc. The $800^{\circ} \mathrm{C}$. Dotted line corresponds to the composition of composition of SAF 2507 indicated by filled square SAF 2507 (from ref. 5). (from ref. 5). 
Isopleth diagrams often give valuable information on the influence of temperature on structure, an example of which is given in Fig 2. The pure duplex region with ferrite $(\delta)$ and austenite is shown to occur in the temperature interval $1000-1400^{\circ} \mathrm{C}$. This temperature interval includes typical temperatures during hot working, i.e. conditions under which the duplex structure is first established. The final structure is established by a diffusion annealing in the range 1200$1300^{\circ} \mathrm{C}$ and a solution heat treatment in the range $1050-1100^{\circ} \mathrm{C}$. The exact temperatures are chosen so as to obtain a partitioning of alloying elements between ferrite and austenite that gives equal pitting resistance in the two phases and the desired fraction of $40-45 \%$ ferrite. Thermo-Calc can be used to assess rather accurately the temperature at which these two conditions are obtained. This is particularly true in the case of pitting resistance equality since the corresponding temperature is sufficiently high to allow near-equilibrium conditions to be attained.

SEM and ATEM can be used in combination to identify the precipitates occurring in isothermally aged materials. ATEM is an invaluable tool for identifying precipitates using electron diffraction and EDX-analysis in combination. An example of convergent beam diffraction patterns from $\chi$-phase is shown in Fig 3. Although basically 2-dimensional, such patterns give 3-dimensional information since the dimension of the c-axis in real space can be calculated from the radius of the first order Laue zone (FOLZ)-ring according to the simple formula $\mathrm{G}=\sqrt{2 K H}$, where $\mathrm{G}$ is the FOLZ radius, $\mathrm{K}$ is inverse wavelength of electrons and $\mathrm{H}$ is the reciprocal lattice spacing parallel to the electron beam (6). The information from electron diffraction in combination with EDX-analysis enables a unique identification and a practically useful "fingerprint" can be obtained. $\chi$-phase is found to contain as much as about $20 \%$ molybdenum while $\sigma$-phase is found to contain about $10 \%$ molybdenum, the precise composition being dependent on time and temperature of formation.

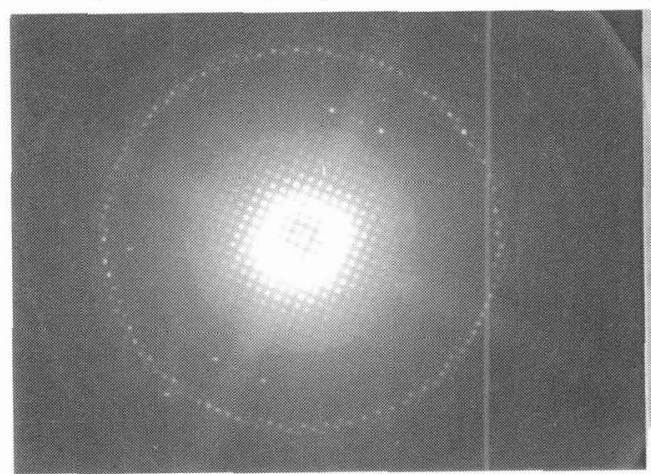

Fig 3 Convergent beam electron diffraction pattern from zone axis $\langle 001\rangle$ of $\chi$-phase (courtesy P. Liu)

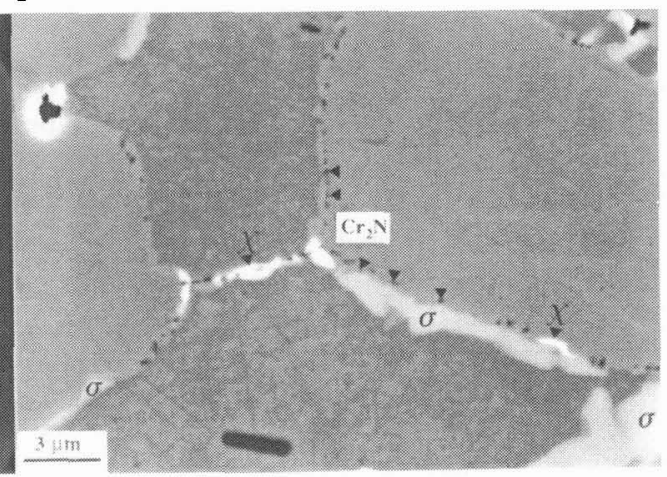

Fig 4 Backscattered SEM of polished surface of SAF 2507 aged for $10 \mathrm{~min}$ at $850^{\circ} \mathrm{C}$, showing atomic number contrast. Particles in bright contrast are $\chi$ phase, while $\sigma$-phase appears in darker contrast (from ref. 5).

Knowing that $\chi$-phase is rich in molybdenum, $\sigma$-phase and $\chi$-phase can be discriminated in SEM using backscattered electrons, which give rise to atomic number contrast. Owing to the strong scattering power of molybdenum, $\chi$-phase appears in brighter contrast than $\sigma$-phase as shown in Fig 4. $\mathrm{Cr}_{2} \mathrm{~N}$ decorating the primary ferrite-austenite phase boundaries are also visible in Fig 4 in darker contrast than the matrix, mainly as a result of the weaker scattering power of 
nitrogen. Based on this type of indirect information on chemical composition, a microstructural survey can conveniently be obtained in SEM for materials with a known set of phases.

At temperatures in the range $300-500^{\circ} \mathrm{C}$ spinodal decomposition of ferrite, usually termed $475^{\circ} \mathrm{C}$ embrittlement, may occur (8). This phenomenon involves the decomposition of ferrite into chromium-rich ferrite, $\alpha$, and iron-rich ferrite, $\alpha$, and is reflected in the microstructure as a modulated contrast in ATEM micrographs. An example of this is shown in Fig 5 in which the contrast arises from the elastic strain fields of $\alpha$ and $\alpha^{\prime}$. Direct evidence of variations in iron and chromium concentrations can be obtained using APFIM. This is shown for a duplex steel of type $22 \% \mathrm{Cr}-5 \% \mathrm{Ni}-3 \% \mathrm{Mo}$ aged for $10 \mathrm{~h}$ at $500^{\circ} \mathrm{C}$ in Fig 6, in which it can be observed that regions that are rich in iron are chromium-poor and vice versa.
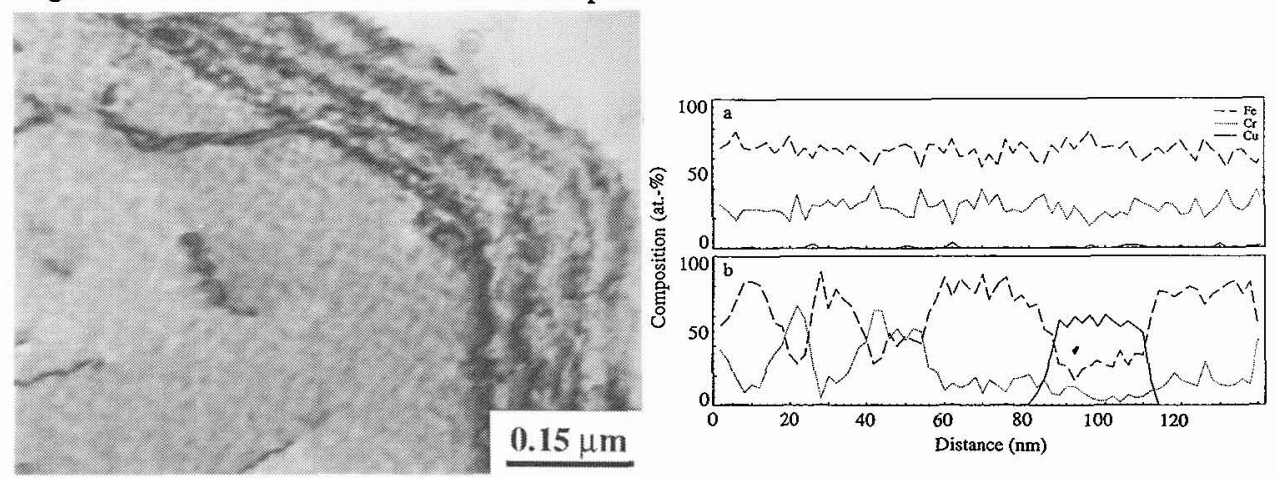

Fig 5 TEM of a $22 \mathrm{Cr}-8 \mathrm{Ni}-3 \mathrm{Mo}$ duplex stainless steel Fig 6 APFIM profile for $\mathrm{Fe}$ and $\mathrm{Cr}$ from ferrite phase aged for $24 \mathrm{~h}$ at $500^{\circ} \mathrm{C}$ : modulated contrast typical of of a $22 \mathrm{Cr}-5 \mathrm{Ni}-3 \mathrm{Mo}$ steel in a) unaged condition and spinodal decomposition is visible in ferrite grain b) material aged for $10 \mathrm{~h}$ at $500^{\circ} \mathrm{C}$ (from ref. 9) (from ref. 7).

After careful microstructural investigations the TTP-diagram can be constructed (see Fig 7). This type of diagram is very important in production since it forms the basis for an assessment of correct process parameters during production. As a matter of fact, this type of information can be used to calculate the corresponding continuous cooling diagram using a computer program developed at Sandvik (10).

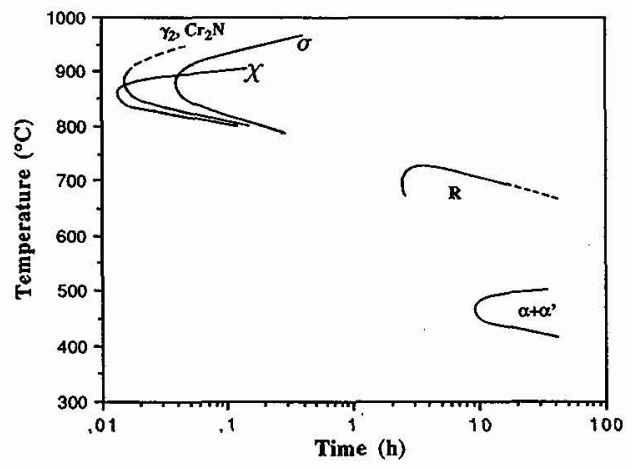

Fig 7 Time-temperature-precipitation curves for various precipitates observed in SAF 2507 (from ref. 5)

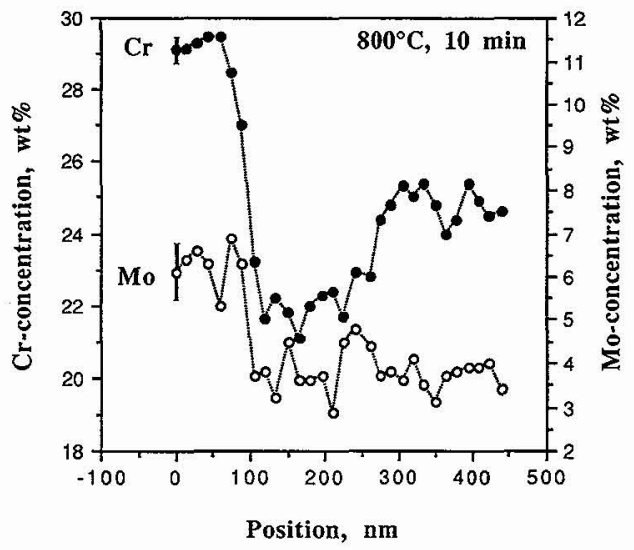

Fig 8 EDX-profile of chromium across secondary austenite in SAF 2507 aged for $10 \mathrm{~min}$ at $800^{\circ} \mathrm{C}$ (from ref. 11) 
As shown in Fig 7 secondary austenite $\left(\gamma_{2}\right)$ is formed in SAF 2507 after isothermal aging at about $800^{\circ} \mathrm{C}$. Corrosion testing according to the ASTM G48 standard has shown that this austenite is particularly sensitive to pitting attack (11). Microanalysis of secondary austenite in ATEM using the EDX-technique revealed that this austenite is poor in chromium compared with the primary austenite (Fig 8). Furthermore, assuming that paraequilibrium exists, ThermoCalc calculations showed that secondary austenite also can be expected to be poor in nitrogen. This explains why secondary austenite in duplex steels is susceptible to pitting attack and also demonstrates how microanalysis in combination with thermodynamic calculations can be used to improve the physical understanding of corrosion behaviour.

\subsection{Non-magnetic spring steel}

The development in the computer and electronics industry towards smaller components with increased performance has created a demand for non-magnetic materials with high tensile strength for applications in electronic devices. Typical products are springs, parts in TV sets and video recorders, memory disc drives in computers and various components in measuring instruments. It is essential in these applications to avoid the formation of strain-induced ' $\alpha^{\prime}$ martensite during cold working. This is accomplished by alloying with manganese and nitrogen, both of which suppress the formation of $\alpha^{\prime}$ and allows non-magnetic $\varepsilon$-martensite to form instead (12).

$\varepsilon$-martensite forms thin laths in the cold worked austenitic matrix whereby significant strain hardening is achieved without the formation of magnetic $\alpha$ '. The $\varepsilon$-martensite can be identified using conventional electron diffraction. The orientation relationship found between the hexagonal $\varepsilon$ and fcc austenite $(\gamma)$ was the expected $\langle 0001\rangle_{\varepsilon} / /\langle 111\rangle_{\gamma}$

It is often convenient to form the final product such as a spring in a relatively soft state after which tempering is performed to achieve the final strength. The manufacturer is therefore interested in a steel with a strong tempering effect, i.e. a large increase in strength as a result of tempering. Tempering in pilot alloys of non-magnetic spring steels similar to 13RM19 resulted in the precipitation of a wide variety of precipitates, namely $\mathrm{M}_{23} \mathrm{C}_{6}$, G-silicide, $\pi$-nitride and $\mathrm{Cr}_{2} \mathrm{~N}$. Convergent beam electron diffraction proved to be quite useful in distinguishing $\mathrm{M}_{23} \mathrm{C}_{6}$ from G-silicide. $\mathrm{M}_{23} \mathrm{C}_{6}$ and G-silicide are both cubic with a lattice parameter close to $11 \AA$. However, $\mathrm{M}_{23} \mathrm{C}_{6}$ has an $\mathrm{Fm} 3 \mathrm{~m}$ structure while $\mathrm{G}$ has an $\mathrm{Fd} 3 \mathrm{~m}$ diamond type structure. The two phases are readily distinguished by comparing diffraction patterns from zone axis $\langle 001\rangle$ since the 200 diffraction spots are dynamically forbidden in the ZOLZ (zero order Laue zone) of $\mathrm{Fd} 3 \mathrm{~m}$ but allowed in the ZOLZ of an Fm3m structure.

Silicon is known to enhance precipitation during tempering. This was confirmed when a number of pilot alloys among non-magnetic steels were compared. For instance, 3.7\% silicon was found to result in a tempering effect of almost $300 \mathrm{MPa}$ while $0.7 \%$ resulted in $175 \mathrm{MPa}$ in two otherwise similar alloys. The results could in part be explained by the large volume fraction of the silicide G-phase in the silicon-rich variant. However, also silicon-free precipitates were quite frequently occurring in this variant indicating that silicon may play an indirect role in the precipitation process. Calculations using Thermo-Calc showed that silicon caused an enhanced activity of carbon and nitrogen that offers a likely explanation for the stronger tempering effect in the silicon-rich alloy (Fig 9). 


\subsection{Stainless maraging steel for surgical needles}

In certain medical applications, such as in the case of surgical needles of various kinds, a combination of mechanical strength, ductility and pitting corrosion resistance is required. Steels used traditionally are martensitic steels of type AISI 420 and austenitic steels belonging to the AISI 300 series. However, the martensitic steels lack ductility at the highest strength levels, while the austenitic steels have insufficient strength. To meet the requirement from the medical market sector concerning a needle steel with improved mechanical properties, the corrosion resistant maraging steel 1RK91 has been developed (13). A strength as high as 3000 MPa can be reached in this steel in combination with a ductility that exceeds that of traditional steels. Furthermore, the increase in strength during tempering approaches $1000 \mathrm{MPa}$ implying that the product can be formed in a relatively soft and ductile condition after which the final strength can be attained by a tempering treatment.

As in the case of non-magnetic spring steel, a strong tempering effect is desirable also in 1RK91. The unusually strong tempering effect in 1RK91 is associated with the precipitation of $\mathrm{Ni}_{3} \mathrm{Ti}$. Because of the small size of these particles, CBED was found to be necessary for identification, an example of which is given in Fig $10 . \mathrm{Ni}_{3} \mathrm{Ti}$ have been found to precipitate as rods on $\{011\}$-planes in $\langle 111\rangle$-directions. There are 12 such combinations of possible positions in a martensitic lattice, whereby an unusually strong tempering effect is achieved.
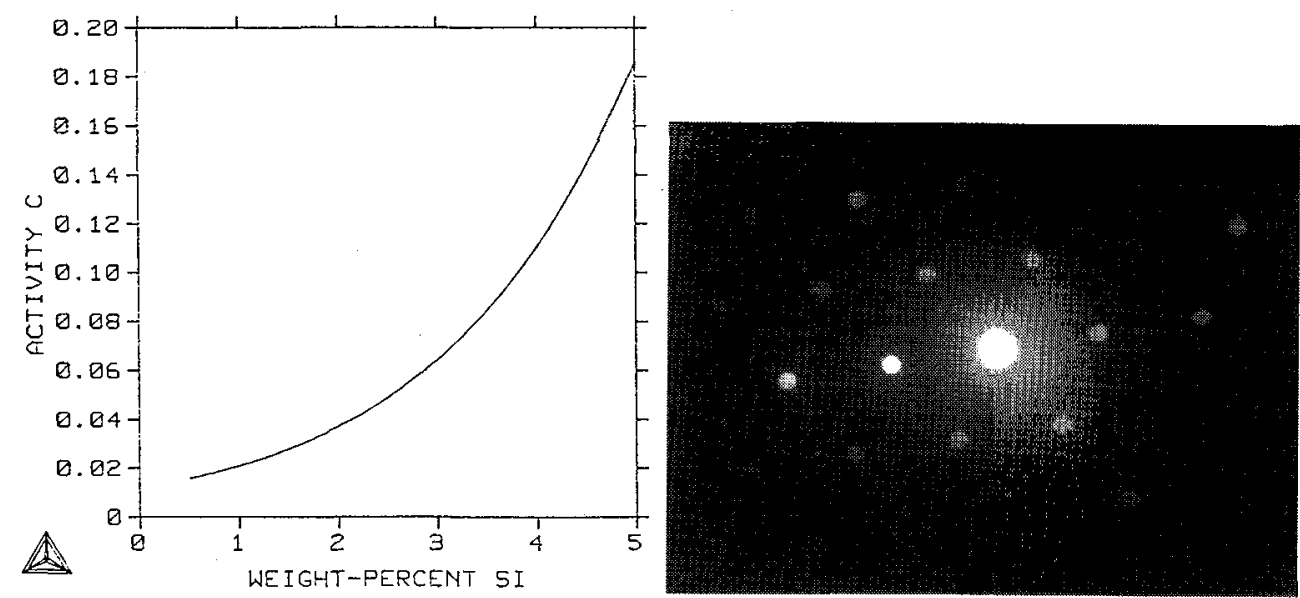

Fig 9 Calculated C-activity as a function of $\mathrm{Si}$ - Fig 10 Microdiffraction of $\mathrm{Ni}_{3}$ Ti precipitates on zone concentration for a $0.05 \mathrm{C}, 4 \mathrm{Mn}, 20 \mathrm{Cr}, 9 \mathrm{Ni}$ and $0.25 \mathrm{~N}$ axis $\langle 0001\rangle$ in $1 \mathrm{RK} 91$ using CBED (courtesy P.Liu) steel (from ref. 12)

\subsection{Alloys for steam generator tubing}

Nickel-base alloys of the types Alloy 600 and 690 have been used extensively in nuclear reactor steam generators. Alloy 600 has been found to be susceptible to environmentallyinduced intergranular stress corrosion cracking (IGSCC) after long term service, while Alloy 690 appears to be almost immune to IGSCC. Several mechanisms of IGSCC in Alloy 600 have been proposed. One of these is the depletion of chromium at grain boundaries. Another is the segregation of impurity elements such as boron and phosphorus to grain boundaries. A third 
mechanism involving methane-induced voids at grain boundaries has recently been proposed. The investigation presented here is a critical examination of a large series of commercial heats using advanced analytical instruments $(14,15)$.

Chromium depletion was observed in Alloy 600 in production annealed material using EDXanalysis in ATEM. However, IGSCC could not be correlated to chromium depletion since there were batches that showed depletion but good performance. Moreover, there were also examples of early failures where no depletion was observed. The observations using ATEM were in agreement with investigations in APFIM, although it should be pointed out that there was one exception; While APFIM showed chromium depletion in the vicinity of a grain boundary by about $4 \%$ units, EDX in ATEM showed no depletion. This observation demonstrates the fact that the lateral resolution of the EDX-technique, about $10 \mathrm{~nm}$, is sometimes insufficient to enable the detection of small scale variations in chemical composition. In such cases, the APFIM is an extremely valuable complement by virtue of its unique resolving power.

SIMS showed segregation of boron and carbon to grain boundaries in all variants of Alloy 600 and Alloy 690, examples of which are given in Figs 11 and 12. Comparison of SIMS boron and carbon ion micrographs and SEM micrographs using back scattered electrons showed that boron and carbon were located essentially to grain boundary segments and intergranular precipitates. This observation was also confirmed by quantitative investigations in the APFIM.

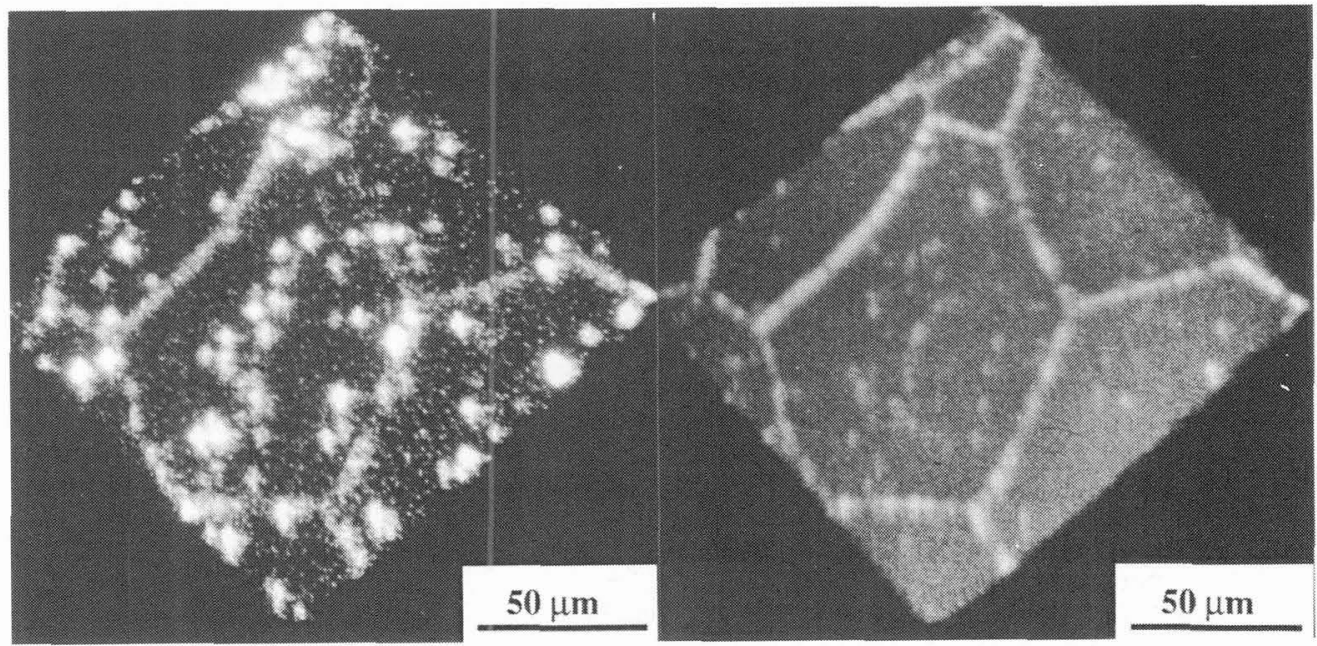

Fig 11 SIMS micrograph of production annealed Alloy 600 showing segregation of carbon to the grain boundary region (from ref. 15)

Fig 12 SIMS micrograph of production annealed Alloy 600 showing segregation of boron to the grain boundary region (from ref. 15)

It is generally accepted that an annealing treatment of steam generator tubes at $715^{\circ} \mathrm{C}$ for 5$12 \mathrm{~h}$ improves the ability to resist IGSCC. It has been suggested that the carbides that precipitate during this treatment are directly responsible for this improvement because of their proposed favourable influence on the stress state in the grain boundary region. An alternative mechanism has been proposed by Shen and Shewmon (16), who envisage cracking during stress corrosion as a result of the formation of grain boundary voids, which in turn are formed as a result of a high methane pressure at grain boundaries. This reaction will be promoted by a 
high concentration of carbon in solid solution, a situation that will occur when the volume fraction of carbides is low.

The perhaps only viable technique for quantifying the concentration of carbon in solid solution in a small volume is atom probe microscopy, since SIMS can only be used for qualitative purposes. The APFIM-results obtained in the present study showed a positive effect of a low concentration in the matrix of dissolved carbon thereby lending experimental support to the void model. Although the mechanism (perhaps several mechanisms) of IGSCC in Alloys 600 and 690 is not definitely assessed this provides an example that illustrates more generally how a combination of analytical instruments can be used in a critical examination of theoretical models.

\section{Concluding remarks}

The aim of this paper has been to illustrate the power of a combined use of various analytical instruments such as SEM, ATEM, SIMS and APFIM and the thermodynamic computer program Thermo-Calc in aquiring a deeper physical understanding of structure-property relations. The scientific understanding of materials behaviour has now advanced to the level where thermodynamically based computer programs such as Thermo-Calc can be used routinely in industrial alloy development.

\section{Acknowledgements}

This paper is published by permission of AB Sandvik Steel. The author appreciates the cooperation over a long period of time with colleagues and co-workers, the names of whom are given in the reference list. In particular, the encouragement of Drs H. Widmark and B. Berglund and the assistance of $\mathrm{Mr} \mathrm{A}$. Wilson in calculating the phase diagrams are gratefully acknowledged.

\section{References}

1. H.-O. ANDRÉN AND H. NORDÉN, Scand. J. Metall., $\underline{8}, 147,(1979)$

2. M.K. MILLER AND G.D.W. SMITH, Atom Probe Microanalysis: Principles and Applications to Materials Problems, Materials Research Society, Pittsburgh, Pennsylvania, (1989)

3. B. SUNDMAN, B. JANSSON AND J.-O. ANDERSSON, Calphad, 9, 153, (1985)

4. H.D. SOlOMON AND T.M. DEVINE, Proc. Conf. "Duplex stainless steels '91", (ed. R.A.Lula), Materials Park, $\mathrm{OH}, \mathrm{ASM}, 693$, (1984)

5. J.-O. NILSSON, Mater. Sci. Techn., $\underline{8}, 685,(1992)$

6. D.B. WILlaMs, Practical Analytical Electron Microscopy in Materials Science, Philips Electronic Instruments Inc., Mahwah, N. J., 1984

7. J.-O. NilsSON AND P. LuU, Mater. Sci. Techn., $\underline{7}$, (9), 853, (1991)

8. M. HILLERT, Acta Metall., $\underline{9}, 525,(1961)$

9. G. WAHLBERG, U. Rolander AND G.L. DUNLOP, Proc. 8th Int. Conf. Strength of Metals and Alloys, ed. P. Kettunen, Pergamon Press, Oxford, 1263, (1988)

10. B. Josefsson, J.-O. Nilsson AND A. Wilson, Proc. Conf. "Duplex stainless steels '91", Les Ulis, France. Les Editions de Physique, 1, 67, (1991)

11. J.-O. NISSON AND A. WISON, Mater. Sci. Techn., accepted for publication

12. H. HolmBerG, J.-O. Nusson AND P. LIU, Trans. ISIJ, 30,594, (1990)

13. A. Hultin Stigenderg and J.-O. NIlsson, Proc. Conf. "Applications of Stainless Steels '92", Stockholm, Sweden, The Institute of Materials, London, 2, 705, 1992.

14. K. Norring, K. Stiller and J.-O. Nilsson, Proc. Conf. "5th Int. Symp. Env. Degr. of Mater. in Nucl. Pow. Syst.", Monterey, USA, American Nuclear Society, Inc. La Grange Park, 111., 482, 1991.

15 K. STILLER, J.-O. NILSSON AND K. NORRING, to be published

16. Y. SHEN AND P.SHEWMON, Met. Trans. A, 22, 1857, (1991) 